supported by Dr. W. B. Carpenter and Prof. T. Rupert Jones. It is needless here to refer more particularly to the controversy that took place regarding this supposed organism ; suffice it to say that for many years the fossil was figured as an organism in most text-books, and was considered to be the oldest evidence of life on the earth. If we turn to Prof. Lapworth's "Intermediate Text-book of Geology, I899," p. 182, we still find a figure of "Eozoon"; but the author remarks: "the organic nature of Eozoön is discredited by most geologists, and the preponderance of scientific opinion has long been in favour of regarding it as a peculiar mineral structure, imitative of the organic." Dawson himself, however, in the Geological Magazine for I895, still boldly upheld the animal nature of Eozoon.

In I88I the Council of the Geological Society awarded to Dr. Dawson the Lyell Medal, the President (Mr. Etheridge) remarking on the value of his researches on the fossil flora of the Carboniferous and older rocks of Canada. In I884 Dr. Dawson published a series of articles, and afterwards a small volume, on the geology of Egypt and Syria, but for the most part his original contributions relate to Canadian geology.

In addition to his Acadian Geology, he was author of several other more or less popular volumes, including "Archaia; or Studies of the Cosmogony and Natural History of the Hebrew Scriptures" (1860); "The Story of the Earth and Man" (1873, and many later editions); "The Dawn of Life" (1875); "Fossil Men and their modern Representatives" (1880) ; "Geological History of Plants" (I888); "Relics of Primeval Life" (1897).

Dr. Dawson was appointed C.M.G. in $188 \mathrm{r}$, and he was knighted in I 884 on the first occasion when the British Association paid a visit to Canada. He was elected President of the Association for the Birmingham meeting in 1886.

He died November 19 , in his eightieth year. His son, Dr. G. M. Dawson, C.M.G., F.R.S., is the distinguished and energetic Director of the Geological Survey of Canada.

H. B. W.

\section{THE LEONIDS.}

THE following communications have reached us with week :reference to the Leonid meteors observed last

\section{MR. DENNING'S REPORT.}

It may be safely said that no meteoric display was ever so generally looked for and awaited with so much interest as the one which has just occurred. That the character of it should have proved disappointing is to be regretted, and especially so after the previous failures in 1897 and 1898 . The astronomical world had been eagerly anticipating the event for many months, and the curiosity of the general public had been excited by articles in the newspapers pointing out, perhaps too confidently, that the meteors would appear in such amazing numbers that the event would form one of the most striking spectacles of a lifetime. Every one therefore sat up to see the shooting stars, but all more or less failed to realise the expectations they had formed. Some people saw nothing, for clouds or fog hid the moon, stars and meteors on the nights of November 14 and 15. Others had a clearer sky and a dazzling moon, but the grand display of meteors was entirely wanting. The constellation of Leo cculd be distinctly seen as it rose higher in the east, but meteoric stars only shot at intervals from the familiar "sickle." We had expected that the whole firmament would be furrowed with these "Leonids," as it was in I799, 1833 and 1866 ; but instead of a heavy bombardment, there was only weak, desultory firing, and when, in the grey dawn of November I6 observers discontinued their vigils, it was with a feelNO. I 569 , vOL. $6 \mathrm{I}]$ ing of regret; moderated, however, by the knowledge that better success might attend similar efforts in 1900 and $\mathrm{I} 9 \mathrm{O}$.

A large number of reports have been received from observers in different parts of the country. Observations were commenced on November 6 by Prof. A. S. Herschel, at Slough, and in three hours he counted twenty-eight meteors after $14 \mathrm{~h}$. on that night, but there was no sign of the Leonids. On November 8 he watched for two hours after I 3 h. $45 \mathrm{~m}$., and saw seventeen meteors, but still no indication of radiation from Leo. On the same night Mr. Besley, at Clapham, watched between Ioh. $55 \mathrm{~m}$. and $13 \mathrm{~h}$. rom., and counted twenty-two meteors, including seven Taurids and possibly two Leonids.

On November Io further observations were secured by Prof. Herschel and Mr. Besley, as well as by Mr. T. H. Astbury, at Wallingford, and by the writer at Bristol. An aggregate of seventy-two meteors was seen, including perhaps two Leonids; but it is often very difficult to identify true Leonids from the same swift, streak-leaving meteors directed from other radiants in the neighbouring region of sky.

On November II, in two hours between $14 \mathrm{~h}$. 30m. and I6h. 3om., the writer at Bristol noted ten meteors, including two certain Leonids. One of these at $\mathrm{I} 4 \mathrm{~h}$. $52 \mathrm{~m}$. was a well-observed foreshortened path from $158^{\circ}+15^{\circ}$ to $160^{\circ}+12^{\circ}$, and would, in combination with the other Leonid, indicate the radiant at $152^{\circ}+23^{\circ}$. If this position is correct the radiant would appear to be a stationary one like that of the October Orionids.

On November 12 the sky was much clouded, but on November I3, between I7h. $8 \mathrm{~m}$. and I7h. 5om., Mr. J. E. Clark, at South Croydon, saw nine meteors (seven Leonids). At Bristol the S.W. sky was partly clear from I $7 \mathrm{~h} .15 \mathrm{~m}$. to $18 \mathrm{~h}$., and five meteors (one Leonid) were counted. At Marlborough between $17 \mathrm{~h}$. 2om. and $18 \mathrm{~h}$. 3om. twenty-one meteors (eighteen Leonids) were seen by Mr. H. Savory. At Cambridge between I7h. and I $8 \mathrm{~h}$. $25 \mathrm{~m}$. twenty-three meteors were counted by $\mathrm{Mr}$. Hinks.

On November I4, Mr. T. H. Astbury, at Wallingford, registered twenty-five Leonids, and saw about a dozen more between $16 \mathrm{~h}$. $3 \mathrm{~m}$. and $17 \mathrm{~h}$. $53 \mathrm{~m}$. Sir W. J. Herschel, at Littlemore, Oxford, saw ninety-eight meteors (sixty-six Leonids) during the night. At Yeovil the sky was generally cloudy, but between $17 \mathrm{~h}$. and $18 \mathrm{~h}$. $30 \mathrm{~m}$. six meteors were seen crossing breaks in the clouds. Both at Littlemore and Yeovil a very fine non-Leonid was seen at 17 h. 4om. At Worthing, Sussex, between I5h. and I 8 h. more than 200 Leonids were counted by Mr. A. R. Schulz. At Cambridge four observers watching from I2h. $5 \mathrm{~m}$. to $16 \mathrm{~h} .35 \mathrm{~m}$. observed forty-five meteors. At Brighton between $14 \mathrm{~h}$. 3om. and $18 \mathrm{~h}$. twenty-eight meteors (twenty-four Leonids) were noted by Dr. R. J. Ryle.

On November I 5, I6 and i7, further observations were made, but meteors fell in very moderate numbers. They appear, in fact, to have been no more numerous than on mid-November nights in ordinary years when the comet is not far from aphelion.

Reports from foreign stations may possibly modify our present views and show that a fairly bright shower was observed elsewhere and during the daytime in England. But from a few descriptions already to hand from America and various parts of Europe it appears that the meagreness of the display formed a common experience even among observers situated in widely different longitudes.

There is every reason to suppose that though the shower has managed to elude us this year it must confront us next year, and possibly in Igor. It will be remembered that there were rich displays in 1866,1867 and 1868 . The one in I 866 occurred ten months after the parent comet of Tempel had passed through its 
perihelion (January $\mathrm{II}$ ), while the shower of I868 appeared nearly three years after the return of the comet. The latter object probably reached perihelion last spring (though it was not observed anywhere), and we are clearly entitled to expect from the great extension of the meteor stream visibly encountered from I866 to I868 that exhibitions of the finest kind will be presented in the two ensuing years. Whether or not the phenomenon will be favourably perceptible in England is uncertain, but it ought to be seen in one of the two years.

In 1833 there was a magnificent display. In 1866 the earth passed through a section of the orbit three months in advance of the part we encountered in 1833 . There was a very rich shower in 1866 , but it was nothing like the preceding one. In 1899 the earth intersected a region of the stream six months in advance of that of I833, and where the meteors are thinly distributed. Everything supports the view that observers will not watch in vain for these meteors in 1900 and 1901 .

When we consider the circumstances affecting the visibility of the Leonids, we must readily concede that it will often evade notice at a given place. In England, November nights are rarely clear and clouds may hide the meteors, or the earth may traverse the swarm at some time during the 15 hours in a day when it possibly could be seen, for from 7 a.m. to after Io p.m. either daylight or an invisible radiant places it beyond reach. But many of us will hope to find compensation for the disappointments of recent years in observing a brilliant return of the meteors in one of the two ensuing years, and certainly before the denser region of the streanı gets too far on its outward journey to aphelion.

\section{W. F. Denning.}

\section{Cause of the Non-appearance of the Shower.}

None of the Leonid meteors are visible until and unless some out of their vast number chance to plunge into our atmosphere and are extinguished after a second or two of intense brilliance. We cannot accordingly follow their motions by observations in the open sky, and can only tell where they are when we can compute where they must be. This has become possible with reference to station $A$ in the stream, that portion through which the earth passed in I866, and of which Adams determined the osculating ellipse as it existed in that year. Any change either in form or position which it has since under. gone has been due to perturbations. The meteors occupying that portion of the stream have nearly completed another revolution since 1866 , November I3. The perturbations they have suffered in the latter part of their course have been computed in Germany by Dr. Berberich, and the perturbations over the whole of the revolution have been computed in this country by Dr. Downing and the present writer, with the aid of the skilled computers of the Nautical Almanac, and at the expense of the Royal Society. These more full computations znable us to follow all the motions of this portion of the stream. It will reach its descending node, where it comes nearest to the earth's orbit, on the $27^{\text {th }}$ of next January, and is accordingly at present advancing towards the earth, along an osculating ellipse of which the present form and position can be determined. This has been done, and it has been thus ascertained that the earth passed the descending node of this orbit last Thursday morning at about 6 a.m. In I866 this orbit intersected the earth's orbit, but unusually intense perturbations have since acted on it, and have so shifted its position that the point when it pierced the plane of the earth's orbit last Thursday, and which we may call point $P$, lay at a disrance from the earth towards the sun which was 0 '0r4I of the mean distance of the sun, that is, it lay about five times farther from the earth than the moon is. A subsidiary investigation, which will shortly be published, makes it almost certain that the point $\mathrm{P}$ indicated above is situated within the stream which was passing the earth last Thursday. This is the only point in the stream which was passing us last Thursday of which we actually know the position ; and it was at the great distance from us which is above stated.

Now comes in another consideration. A separate dynamical investigation into the conditions under which the Leonids were drawn into the solar system by Uranus, has shown that when that planet advanced along his orbit and left them behind, they found themselves moving nearly with the same speed and nearly in the same direction, but not quite. They were in fact scattered over a very small cone of dispersion. This occasioned small differences to exist between the vast elliptic orbits round the sun, upon which they then entered. Some of the meteors found themselves in planes slightly more inclined to the ecliptic than others, some started along ellipses of slightly greater ellipticity, and so on; but all when they had travelled along the inward part of their new elliptic journeys would cross the plane of Uranus's orbit (which is nearly the plane of the earth's orbit) at points which lay along the line of nodes, measured in the plane of Uranus's orbit, a line which nearly coincided with the radius of the earth's orbit, which lay along the line of nodes in the plane of the ecliptic. Hence the stream became a ribbon-shaped stream at its descending node, where the earth encounters it, the width of the ribbon lying very nearly along one of the radii of the earth's orbit. The position of this ribbon has been somewhat altered by the perturbations to which it has been exposed during the seventeen centuries and threequarters which have since elapsed. Its width accordingly no longer lies quite perpendicular to the earth's orbit. We know that the stream has this ribbon shape, but we do not know its width further than that it is considerable, nor do we know where in the width of the ribbon the point $P$ lies whose position we have been able to determine. That we have not had one of the great Leonid showers this year conclusively proves that the part of the width of the ribbon which lies outside the point $\mathrm{P}$ has not been able to reach the whole way out to the earth's orbit-a distance of about I,300,000 miles.

G. Johnstone Stoney.

\section{Greenwich Observations.}

The Astronomer Royal reported to the Times on the 16 th inst., that the preparations made at Greenwich for observing the Leonid meteors were rendered abortive by cloud and fog on the nights of November I4-I5 and I5-I6. During a short break in the clouds on the morning of the 16th only 16 Lennids were noted (by four observers) in $42 \mathrm{~min}$. from $5 \mathrm{~h}$. $34 \mathrm{~min}$. to 6h. I6min. A.M. November I6. No photographs could be obtained.

Report from the Solar Physics Observatory.

To take advantage of the meteor shower that was expected at the earlier part of last week, the whole staff of the Solar Physics Observatory took part in a carefully-prepared programme. The observers were divided up as follows : The six-inch Dallmeyer camera for photographing the radiant point, and a siderostat with three small cameras mounted on its polar axis for obtaining spectra were worked by Dr. Lockyer and Mr. Howard Payn, who was a volunteer. Mr. Fowler took charge of an integrating spectroscope and a small visual spectroscope mounted equatorially to examine bright trails. The large 6 -inch prismatic camera was used by Mr. Baxandall and Mr. Shackleton on alternate nights, while a 9-inch prismatic reflector and another battery of small cameras was worked by Mr. Butler and Mr. James.

On all the four nights ( 9 p.m. to 6 a.m.) during which a watch was kept, the weather was very unfavourable, and it was only for short periods of time on Wednesday and Thursday that a glimpse of the sky was at all possible. In fact, fog and cloud seemed to alternate or combine at the expense of a clear sky. To take advantage of a clear sky at some distance from the observatory, such as at Hampstead, several volunteers took up their positions there with advantage. At the observatory itself no photograph of any meteor trail or spectrum was obtained, and it was practically only for a short period on Thursday morning that plates were actually exposed with any prospect of success. Eye observations indicated, however, that if the shower had arrived on Wednesday or Thursday, at least some trace of its presence would have been seen during the period of observation, in spite of the fog, if the display had attained anything like its grandeur of 1866 .

Tuesday night was apparently very clear at Hampstead, and one of our keen amateurs reported that between Io p.m. and 4 a.m. the next morning, there was an absolute dearth of meteors. Another observer on Banstead Downs also saw no signs of the shower, for between $2.28 \mathrm{a} . \mathrm{m}$. and $3 \mathrm{a} . \mathrm{m}$. on the Wednesday morning, he counted only ten meteors, and these might not all have been Leonids. Brighton had a clear sky on the morning of Wednesday, and an observer there who watched No. I 569 , vOL. 6I ] 
between midnight and 4 a.m. saw no evidence of a display but sixteen Leonids and a few sporadic meteors. Several other observers who observed from Hampstead Heath on the Thursday morning early also reported no shower, but simply a meteor or two.

It must be concluded therefore that the expected shower did not arrive, or rather that the earth has not passed through any very dense portion of the swarm. It may be recollected that in the two preceding Novembers the Leonids were conspicuous by their absence, and this may practically be said of the recent display.

In addition to the above reports, the communications printed below have been received :-

Mr. E. C. Willis, of Ipswich, reports as follows :

November I 7 :-

\begin{tabular}{|c|c|c|c|c|c|}
\hline & Time. & 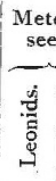 & 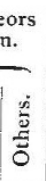 & Remarks on weather. & \\
\hline $\begin{array}{l}12 \\
13 \\
14 \\
16 \\
17 \\
17 \\
17 \\
17\end{array}$ & $\begin{array}{rr}5-12 & 45 \\
0-13 & 20 \\
0-14 & 25 \\
45-17 & 0 \\
0-17 & 15 \\
15-17 & 30 \\
30-17 & 45 \\
50-18 & 5\end{array}$ & $\begin{array}{r}1 \\
0 \\
1 \\
10 \\
4 \\
8 \\
8 \\
12 \\
2\end{array}$ & $\begin{array}{l}0 \\
0 \\
0 \\
4 \\
1 \\
3 \\
6 \\
2\end{array}$ & \begin{tabular}{|c} 
Thick mist \\
Very thick mist \\
Thick mist \\
Fine \\
Fine, with some cloud \\
Fine \\
Fine \\
Fine, sky much lighter
\end{tabular} & Moonlight. \\
\hline
\end{tabular}

November I5.-Observed occasionally from IIh. to I $8 \mathrm{~h}$. The clouds at times covered the entire sky, while at times they were much broken up. No meteors were seen. The conditions were such that a brilliant shower could not have passed unobserved.

November 16.-Observed from I1.40 till 12. IO. The sky was mostly covered with cloud. No meteors were seen.

The following notes by the Rev. Martin Wall, Fort Augustus, N.B., have been received from the Meteorological Office :-

"Great meteor" seen at 8.20 p.m., November I 5 . Flying with tremendous velocity south-east to north-west. Described, by an engineer, as a mass of flame of between 2 and 3 feet square ; in brilliancy like the arc-light; leaving a trail of flame in its course, and lighting up the sky with a white light. It was seen by a second person to explode, over hill to north-west.

[N.B.-Indoors, where the electric light was burning, the diffused light of the meteor was distinctly noticeable.]

Two or three Leonid meteors were seen on the night of November 14 (one or two at 2 a.m., and one at 5.45); but the I 5 th and 16th were totally clouded over; hence photographic preparations were of no avail. I4th.]

[N.B.-Numerous ordinary meteors were also seen on the

\section{NOTES.}

THE scientific lessons of the war are crowding upon us. We have already referred to the blunder made by our military authorities, in not sending Marconi apparatus to South Africa among the first equipments. We now learn indeed, after the investment of Ladysmith is drawing to a close, that Marconi apparatus is being sent out. The silence of Ladysmith during the last eventful weeks will point the moral, which is not likely to be forgotten in the future; and it may well be that in the movements about to take place, in which the Ladysmith and the relieving force should be able to work in concert, the absence of a sure and rapid method of signalling, the absence of the Marconi apparatus, may render this difficult if not impossible. We have been informed on good authority that some time ago the importance of a locomotive search-light in operations of war was strongly represented to the military NO. I 569, vOL. 6I] authorities; but they would have none of it. Fortunately, however, the naval force in Natal has now provided the army with one. It is certain to do good service.

THERE can be little doubt that the presence of another scientific instrument, the balloon at Ladysmith, has saved the situation. A moment's consideration of what this touch of science can do for us will indicate that the above expression is well grounded. Imagine two identical maps of Ladysmith and its surroundings, including the region dominated by our guns, carefully marked with squares, so that the position of any patch can be exactly defined by the rectangular coordinates shown at the side. AI, A20, \&c., X6, $Z_{30}, Z_{40}$, \&c. Imagine one of these in the hands of an officer who knows the ground thoroughly well, in the car of the captive balloon. He telephones the position of the enemy to the officer commanding the artillery down below, who is possessed of an identical map. From this he can at once determine the azimuth and range, and in a few minutes the shell may be fired in the required direction. The telephone of the balloon will inform the gunners how the shell has been dropped, and any directions regarding range can be given. It will therefore be impossible for the rebels, thanks to the balloon, to form in daylight in any large numbers for an attack on the camp, without rendering themselves liable to the searching fire of the guns. May we hope therefore that the balloon will alsc be used along the chief line of advance? During a calm day it is possible that this scientific instrument may be far more valuable than an army of scouts, though the difficulties attending its working are fully recognised. Seeing then how important scientific instruments are in this struggle, in which millions are freely spent, we return to our question, how is it that there is no scientific committee to advise the Government in such matters, even if only to anticipate scientific applications? and how is it that from the Grand Council of the nation, the Privy Council, men of science are rigorously excluded ?

A CONFERENCE of representatives of electric railway and electric tramway enterprises on the one hand, and representatives of the Government interested in the Greenwich and Kew Observatories on the other, was held at the Board of Trade on Wednesday in last week. The object of the conference was to ascertain the best means of dealing with the interference with the delicate instruments in the observatories by the leakage which there is reason to believe will follow from the introduction of large systems of electric traction. After Sir Courtenay Boyle had opened the proceedings, Prof. Rucker and the Astronomer Royal showed that magnetic instruments are seriously affected by the proximity of systems of electric traction ; but Sir Douglas Fox and Major Cardew would not admit that any interference with observatory instruments had at present been proved. As a result, a committee was appointed " to investigate the amount of magnetic disturbance produced in the neighbourhood of electric tramways and railways constructed and worked under the Board of Trade regulations ; and to report as early as possible." The committee consists of Profs. Rucker, Ayrton and Perry, representing the laboratories; Prof. Kennedy, Mr. H. F. Parshall, Major Cardew and Mr. Brousson, for the electric traction companies; and Mr. A. P. Trotter for the Board of Trade.

The Paris correspondent of the Chemist and Druggist makes the following announcement:-The Professorship of Inorganic Chemistry at the Paris School of Pharmacy, vacant by the retirement of Prof. Riche, has been given to M. Henri Moissan. The latter's appointment as professor of toxicology at the School, which he already held, was perhaps due more to a very natural desire to attach the brilliant professor to the teaching staff than to poisons being his forte. He will now lecture on the subject that has practically been his life study. His first lesson on 